ABREU, R.G. et al. Técnica comparativa de biopsia ovariana em éguas. PUBVET, Londrina, V. 5, N. 26, Ed. 173, Art. 1165, 2011.

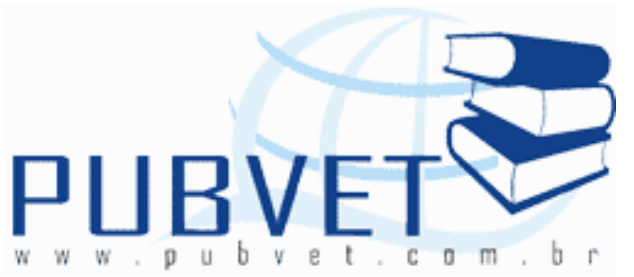

PUBVET, Publicações em Medicina Veterinária e Zootecnia.

\title{
Técnica comparativa de biopsia ovariana em éguas
}

Roberto Gebe Abreu1 ${ }^{1}$, José Frederico Straggiotti Silva², Eulógio Carlos Queiroz de Carvalho ${ }^{3}$, Eduardo Shimoda ${ }^{4}$

1Doutorando Ciência Animal, LRMGA/UENF - RJ. robertogebe@yahoo.com.br

${ }^{2}$ Prof. Dr. LRMGA/UENF - RJ

${ }^{3}$ Prof. Dr. LMPA/UENF - RJ

${ }^{4}$ Prof. Dr. UCAM/Campos - RJ

\section{Resumo}

As alterações cíclicas e comportamentais na reprodução das éguas podem estar relacionadas, em número considerável, às alterações ovarianas. Procedimentos comparativos com a forma padrão de colheita de material para biopsia, quando da exérese cirúrgica ou de necropsia, determinam melhor qualidade na avaliação dos resultados. A colheita de amostra de ovário para biopsia com uso de agulha cortante tipo Trucut, foi experimentado em peças de abate escolhidas aleatoriamente no frigorífico Itapetinga, em Itapetinga BA. Definindo planos teciduais pela variação morfológica da disposição celular (celular denso, turgido e colagenizado), e realizando a comparação dos resultados, em relação à forma padrão de colheita, que não diferiram significativamente, demonstra-se a representatividade da nova técnica. Três modos de avaliação foram utilizados para comparar os planos teciduais dentro da mesma amostra (percentagem de área ocupada por células, nível 
ABREU, R.G. et al. Técnica comparativa de biopsia ovariana em éguas. PUBVET, Londrina, V. 5, N. 26, Ed. 173, Art. 1165, 2011.

organizacional das células, cromatismo do núcleo celular), resultando em diferenças significativas entre as áreas dos planos teciduais por amostra. Conclui-se que esta é uma nova abordagem no uso de procedimentos menos invasivos e traumáticos, quando da colheita de amostra para biopsia ovariana em éguas, podendo futuramente associar-se às cirurgias minimamente invasivas, como as cirurgias endoscópicas transluminais por orifícios naturais (NOTES).

Palavras-chave: Biopsia, Trucut, ovário.

\section{Comparative technique of ovarian biopsy in mares}

\section{Abstract}

The cyclic changes in reproduction and behavior of mares may be related, in considerable numbers, ovarian changes. Comparative procedures with the standard form of blood sampling for biopsy, when surgical excision or necropsy, determine quality in evaluating the results. The sample collection for ovarian biopsy using a needle sharp Trucut type, was tested in randomly selected pieces of slaughterhouse Itapetinga in Itapetinga - BA. Defining tissue planes by the morphology of the provision (cellular dense, turgid and collagenized), and performing the comparison of results in relation to the standard form of harvest, which did not differ significantly, demonstrating the representativeness of the new technique. Three modes of assessment were used to compare the tissue planes within the same sample (percentage of area occupied by cells, the organizational level of cells, chromaticism of the cell nucleus), resulting in significant differences between the areas of tissue planes per sample. We conclude that this is a new approach to the use of less invasive procedures and trauma, when the sample collection for ovarian biopsy in mares and may eventually join the minimally invasive surgeries, such as for transluminal endoscopic surgery natural orifices (NOTES).

Keywords: Biopsy, Trucut, ovary 
ABREU, R.G. et al. Técnica comparativa de biopsia ovariana em éguas. PUBVET, Londrina, V. 5, N. 26, Ed. 173, Art. 1165, 2011.

\section{Introdução}

Fertilidade é um termo genérico que define apenas a capacidade dos indivíduos de procriar ou perpetuar a espécie. A eficiência reprodutiva passa a ser a fertilidade expressa no maior número de nascimentos, em menor período (MARTINS et al. 2002).

Considerada uma função fisiológica elitista, a reprodução eqüina, por requerer o adequado funcionamento dos demais sistemas e funções biológicas (RICKETTS, 2005), pode ser prejudicada por afecções ovarianas, dentre elas, podemos citar: hematomas, abscessos, torções de ovário e distúrbios neoplásicos (tumores de células germinativas, tumores mesenquimatosos, tumores das células da granulosa ou da teca). Estas afecções podem causar alterações no comportamento e no ciclo estral, relacionados ao metabolismo hormonal envolvido. Neste contexto, o exame ginecológico é indispensável para diagnosticar as alterações presentes e proceder o diagnóstico. $O$ exame consiste na avaliação do histórico reprodutivo da fêmea, inspeção geral e específica, palpação retal e ultrassonografia (GRUNERT \& GREGORY, 1984; VAN CAMP, 1992; PIMENTEL et al. 1998).

Nas éguas, as avaliações clínicas dos ovários, podem seguir à colheita de amostra para histopatologia, oriundas de peça cirúrgica (PC), ou peça de necropsia (PN). Devido à carência de informações sobre o tema e à ausência de estudos que confrontem técnicas de biopsia (NÉSPOLI et al. 2010), o exame histopatológico obtido através de biopsias é essencial para o estabelecimento de diagnósticos e prognósticos mais precisos (BUNCH et al. 1985). A escolha da agulha de biopsia Trucut se deu em função das dimensões mínimas da amostra colhida pela "gaveta", em comparação ao método padrão de colheita, que se utiliza de lâmina cortante, cuja amostra tem maiores dimensões.

O objetivo do presente trabalho é realizar a colheita de material ovariano, em peças anatômicas provenientes de abatedouro, através de biopsia com agulha Trucut e realizar análise histológica, para buscar uma 
ABREU, R.G. et al. Técnica comparativa de biopsia ovariana em éguas. PUBVET, Londrina, V. 5, N. 26, Ed. 173, Art. 1165, 2011.

relação com as alterações funcionais reprodutivas. Além disso, objetiva-se determinar se a representatividade da amostra colhida, por este método, tem resultados semelhantes em relação à amostra colhida pelo método padrão.

\section{Materiais e métodos}

Local - Os procedimentos de colheita de amostra foram realizados no Frigorífico Itapetinga, em Itapetinga - BA. Os exames histopatológicos foram realizados no Laboratório de Morfologia e Patologia Animal da Universidade Estadual do Norte Fluminense Darcy Ribeiro (UENF).

Animais - Foram utilizados ovários provenientes de 20 éguas SRD, idades entre 05 - 15 anos, escolhidos aleatoriamente do lote diário da linha de abate.

Colheita do Sistema Reprodutivo - Na linha de esfola das carcaças, as vísceras retiradas seguem por esteira mecânica para a separação de partes (miúdos, graxaria e laboratório). Neste momento ocorre a captação do aparelho reprodutor feminino (vulva, vagina, cérvix, útero, ovários), e encaminhado à área reservada para manuseio. As peças anatomicamente intactas - livres de degenerações/cortes mecânicos - foram utilizadas para colheita de amostras.

Biopsia ovariana - Os ovários numerados foram seccionados medialmente para que cada parte seja utilizada por uma técnica diferente de colheita, Trucut e padrão respectivamente. Foram fotografados para arquivo aos pares, sendo cada parte de um lado, direito e esquerdo. Foram individualmente manipulados para a introdução de agulha de biopsia tipo Trucut (Gallini, TZ 14/10, Itália), semi-automática, que direcionada além da punção folicular, posiciona a "gaveta" da agulha no espaço entre o antro folicular e o parênquima central, que é o tecido cortical, particularidade anatômica do ovário equino. A "gaveta" da agulha colhe um fragmento tecidual com dimensões $18,0 \times 2,0 \times 1,5 \mathrm{~mm}$. A ação da agulha Trucut é demonstrada na Fig.1. 
ABREU, R.G. et al. Técnica comparativa de biopsia ovariana em éguas. PUBVET, Londrina, V. 5, N. 26, Ed. 173, Art. 1165, 2011.

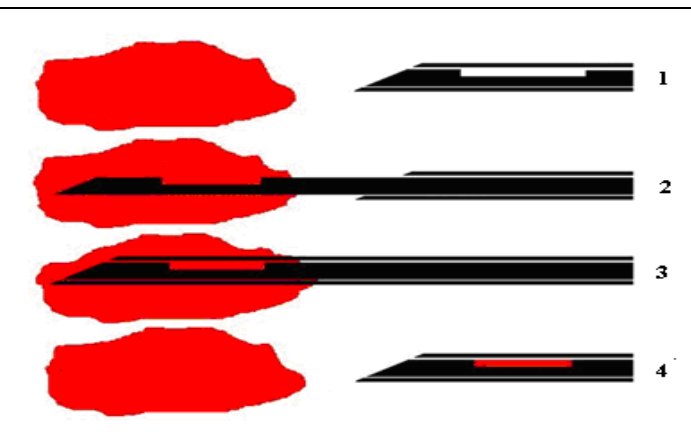

Figura 1- Modo de ação da agulha de biopsia Trucut: 1.Bainha e agulha com "gaveta" para o fragmento; 2.A agulha é tracionada para o ponto desejado; 3.A bainha desliza sobre a agulha para captura do fragmento; 4.Retirar agulha, bainha e fragmento. Fonte: Michael Edwards, 2003

As amostras de biopsia foram retiradas da "gaveta" e acondicionadas em frascos com o número de identificação do animal, contendo solução de formol 10\% tamponado. Da mesma forma, fragmentos dos mesmos ovários, colhidos pelo método padrão, também foram acondicionados e identificados para avaliação comparativa. No procedimento padrão, a biopsia ovariana é realizada com bisturi convencional para obtenção de amostras com dimensões próximas de 15,0 x 5,0 x 5,0 mm, neste estudo, devido a flacidez tecidual das peças.

Os fragmentos de biopsia foram processados no Laboratório de Morfologia e Patologia Animal da Universidade Estadual do Norte Fluminense Darcy Ribeiro (UENF).

Processamento das amostras - As amostras colhidas foram fixadas em formol $10 \%$ tamponado por 12 horas. Após a fixação, as amostras passaram pelo processamento histopatológico de rotina para inclusão em parafina desidratação, diafanização e impregnação (HUMASON, G.L. 1972). Cortes micrométricos foram realizados após, com 4,0 a 6,0 $\mu \mathrm{m}$ de espessura e as fitas colocadas em banho-maria. Após distensão destas, foram transferidas para lâminas de vidro recobertas com fina camada de albumina, facilitando a adesão e iniciando a montagem. A técnica de coloração das lâminas utilizou os corantes Hematoxilina e Eosina (HE). A colocação de uma gota de resina líquida sobre o corte aderido e, cobrí-lo com lamínula, encerraram o 
ABREU, R.G. et al. Técnica comparativa de biopsia ovariana em éguas. PUBVET, Londrina, V. 5, N. 26, Ed. 173, Art. 1165, 2011.

processamento das amostras para posterior análise através de microscopia ótica.

Análise Microscópica - As lâminas foram observadas à luz da microscopia ótica (Microscópio OLYMPUS BX41, modelo U-MDOB3, Japão), na amplificação de 20x. Imagens fotográficas foram obtidas por câmera fotográfica digital (NIKON COOLPIX 995, Japão) acoplada, utilizando objetiva com aumento de 20x e zoom F4.5.

Após a análise e definição das estruturas presentes nas lâminas, por ambas técnicas de colheita, os planos teciduais das amostras foram observados e analisados isoladamente. Os planos teciduais ovarianos definidos inicialmente para avaliação foram:

1- Celular denso (Distribuição celular sem polaridade, núcleo ovóide, não se modela)

2- Turgido (Distribuição celular monótona, núcleo rarefeito, próxima ao folículo)

3- Colagenizado (Distribuição celular em feixe modelado, núcleo fusiforme)

A partir da definição dos planos teciduais ovarianos, a primeira avaliação comparativa entre os métodos de colheita foi em relação a percentagem (\%) de área ocupada por células em cada plano tecidual (Pixel Analyser 6.6).

A falta de material publicado sobre o tema abordado, fez com que técnicas de avaliação fossem criadas para o desenvolvimento do estudo.

Partindo-se de uma avaliação simples, que também pode diferenciar os três planos teciduais, utilizou-se uma escala de 0 - 5, em relação ao nível organizacional das células, numa distribuição que pode ser interpretada:

- De $0-1$ = Distribuição em feixe modelado, núcleo fusiforme;

- De 2 - 3 = Distribuição monótona, núcleo rarefeito;

- De $4-5$ = Distribuição sem polaridade, não se modela. 
ABREU, R.G. et al. Técnica comparativa de biopsia ovariana em éguas. PUBVET, Londrina, V. 5, N. 26, Ed. 173, Art. 1165, 2011.

Partindo-se novamente de uma avaliação simples, para diferenciar os três planos teciduais, utilizou-se uma escala de $0-5$, em relação ao cromatismo do núcleo celular, numa distribuição que pode ser interpretada:

- De $0-1$ = Hipocromatismo;

- De $2-3$ = Normocromatismo;

- De $4-5=$ Hipercromatismo.

Os 40 ovários coletados geraram 80 lâminas histológicas (uma amostra colhida com agulha Trucut e uma amostra colhida segundo o método padrão, por ovário), e foram selecionados 09 pares de lâminas correspondentes (18), após a classificação dos planos teciduais - celular denso, turgido e colagenizado - gerando 54 imagens para avaliação comparativa e também estatística.

Formatação gráfica das lâminas - Tratamento de imagens - Para o tratamento de imagens foi utilizado o aplicativo Pixel Analyser 6.6, que determinou a tonalidade de cada pixel da imagem escolhida. $O$ resultado gerou um arquivo de texto (extensão .txt), em que cada linha corresponde à tonalidade de cada pixel, com os valores das tonalidades variando de 0 - 1. Este arquivo de saída do Pixel Analyser 6.6 gerou, com auxílio inicial do SAEG 9.1, a análise de freqüência simples para um novo arquivo contendo as freqüências de pixels por tonalidade. Por dispersão simples, construiu-se o gráfico para determinação do limiar a partir da curva de $4^{\circ} \mathrm{grau}$ ( 0 corresponde ao preto e 1 corresponde ao branco) - Limiar $=0,70$. Obteve-se assim o percentual de pixels pretos e brancos na imagem.

Análise estatística - A análise estatística foi feita através do aplicativo SAEG 9.1, e foram obtidos parâmetros da estatística descritiva - média, erro-padrão, intervalo de confiança $(P=0,95)$ e coeficiente de variação (PIMENTEL GOMES, 1966) - das tonalidades dos pixels, de acordo com o plano tecidual e método 
ABREU, R.G. et al. Técnica comparativa de biopsia ovariana em éguas. PUBVET, Londrina, V. 5, N. 26, Ed. 173, Art. 1165, 2011.

de colheita: Percentagem de área ocupada por células; Nível organizacional das células; Cromatismo do núcleo celular.

Os testes Tukey e " $t$ ", ao nível de $5 \%$ de probabilidade, foram utilizados.

\section{Resultados}

Utilizando-se uma técnica inédita em ovários equinos, com agulha de biopsia Trucut, obteve-se fragmentos dos ovários com alta representatividade para avaliação comparativa. A Tab.1 e Fig.2 demonstram a primeira avaliação.

Tabela 1 - Percentagem da área ocupada por células de acordo com o plano tecidual e o método de colheita em amostras de ovários de éguas.

\begin{tabular}{ccccccc}
\hline \multirow{2}{*}{ Animal } & \multicolumn{4}{c}{ Área (\%) ocupada por células de acordo com o plano tecidual e o método de coleta } \\
\cline { 2 - 6 } & \multicolumn{2}{c}{ Celular denso } & \multicolumn{2}{c}{ Turgido } & \multicolumn{2}{c}{ Colagenizado } \\
\cline { 2 - 6 } & Trucut & Padrão & Trucut & Padrão & Trucut & Padrão \\
\hline 1 & 44,05 & 31,77 & 35,42 & 16,05 & 17,67 & 17,42 \\
2 & 56,48 & 32,04 & 18,96 & 20,09 & 13,57 & 17,47 \\
3 & 35,45 & 32,65 & 17,82 & 18,25 & 29,36 & 20,29 \\
4 & 35,89 & 43,68 & 23,89 & 12,56 & 13,61 & 15,05 \\
5 & 49,07 & 38,92 & 15,98 & 29,42 & 17,16 & 18,57 \\
6 & 40,94 & 50,15 & 26,66 & 21,87 & 39,81 & 29,69 \\
7 & 47,29 & 46,21 & 37,41 & 21,44 & 33,88 & 17,48 \\
8 & 41,01 & 49,25 & 38,52 & 22,08 & 28,55 & 17,11 \\
9 & 42,68 & 39,98 & 45,42 & 23,84 & 21,71 & 13,69 \\
\hline $\mathrm{X} \pm \mathrm{s}(\mathrm{X})$ & $43,7 \pm 2,2$ & $40,5 \pm 2,4$ & $28,9 \pm 3,5$ & $20,6 \pm 1,6$ & $23,9 \pm 3,1$ & $18,5 \pm 1,5$ \\
CV (\%) & 15,2 & 18,0 & 36,7 & 23,2 & 39,3 & 24,8 \\
IC & $38,6-48,8$ & $34,9-46,1$ & $20,7-37,1$ & $16,9-24,3$ & $16,7-31,1$ & $15,0-22,0$ \\
\hline$X \pm s(X):$ média \pm erro-padrão; CV (\%): coeficiente de variação; IC: intervalo de confiança (P=0,95)
\end{tabular}


ABREU, R.G. et al. Técnica comparativa de biopsia ovariana em éguas. PUBVET, Londrina, V. 5, N. 26, Ed. 173, Art. 1165, 2011.

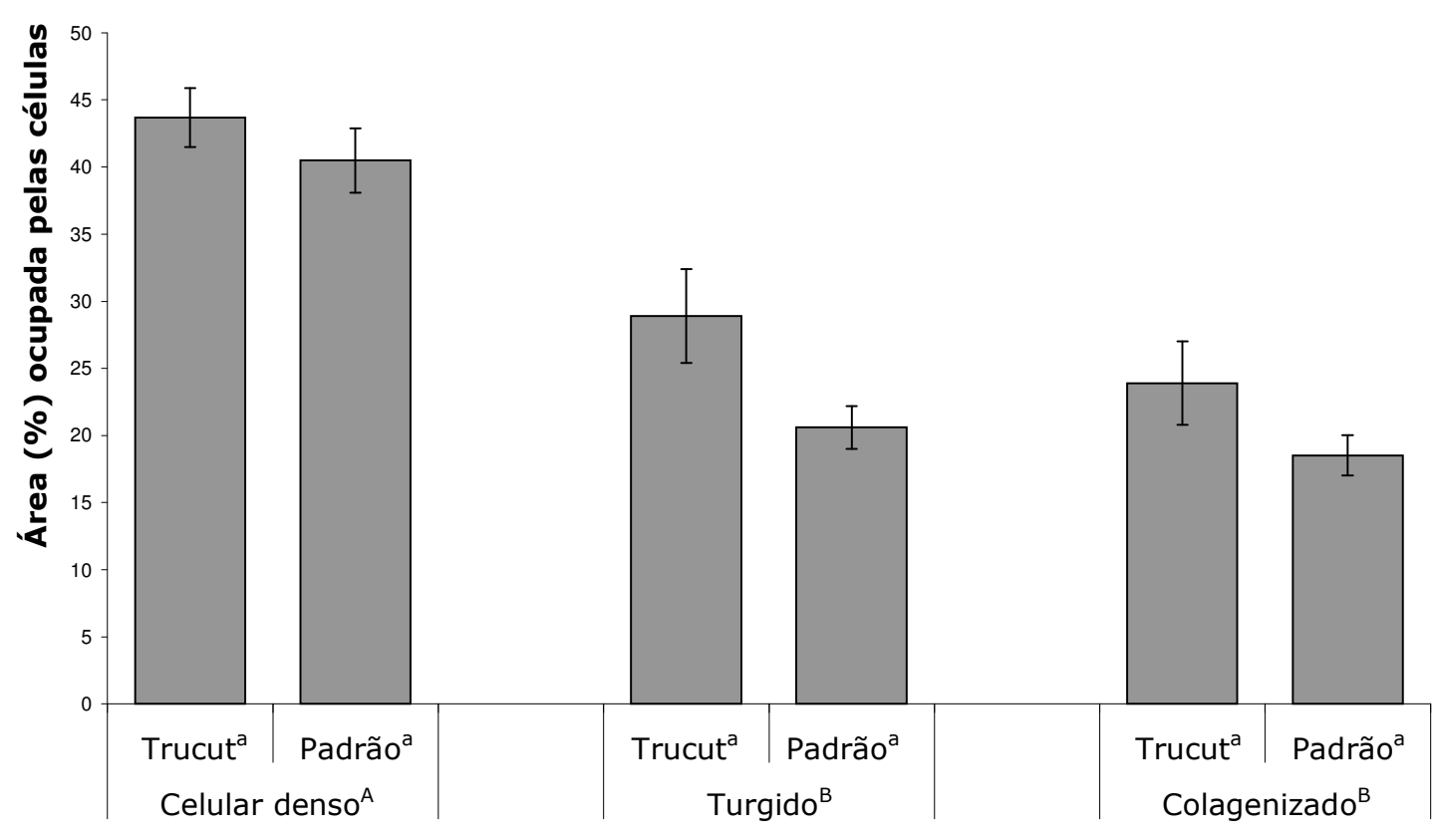

Plano tecidual e método de colheita

Figura 2 - Percentagem da área ocupada por células de acordo com o plano tecidual e o método de colheita em amostras de ovários de éguas.

Apesar dos valores das médias $(X)$ de percentagem de área ocupada por células ter sido maior quando se utilizou o método Trucut, nos três planos teciduais, os valores não diferiram estatisticamente do método Padrão. Tal observação pode ser explicada pelo mecanismo de funcionamento da agulha de colheita Trucut, devido a rapidez da ação do disparo e compressão tecidual, ao envolver o fragmento alojado na "gaveta", pela bainha cortante.

Em relação aos planos teciduais, os planos turgido e colagenizado não diferiram significativamente entre si (Fig.2), mostrando a necessidade de novos parâmetros para o comparativo, uma vez que a percentagem de área ocupada por células não serve como diferencial para estes dois planos teciduais.

A Tab.2 e Fig.3 demonstram a segunda avaliação, e os resultados da análise estatística confirmaram $(p<0,05)$ a diferenciação entre os planos teciduais com relação ao nível organizacional das células em amostras de 
ABREU, R.G. et al. Técnica comparativa de biopsia ovariana em éguas. PUBVET, Londrina, V. 5, N. 26, Ed. 173, Art. 1165, 2011.

tecido ovariano em éguas, e que, o método de coleta não influenciou diretamente o resultado (Fig.3).

Tabela 2 - Nível organizacional das células de acordo com o plano tecidual e método de colheita em amostras de tecido ovariano em éguas.

\begin{tabular}{|c|c|c|c|c|c|c|}
\hline \multirow{3}{*}{ Animal } & \multicolumn{6}{|c|}{ Nível organizacional das células $(0-5)$} \\
\hline & \multicolumn{2}{|c|}{ Celular denso } & \multicolumn{2}{|c|}{ Turgido } & \multicolumn{2}{|c|}{ Colagenizado } \\
\hline & Trucut & Padrão & Trucut & Padrão & Trucut & Padrão \\
\hline 1 & 5 & 4 & 3 & 3 & 1 & 0 \\
\hline 2 & 4 & 5 & 3 & 3 & 0 & 1 \\
\hline 3 & 4 & 5 & 3 & 3 & 0 & 1 \\
\hline 4 & 5 & 4 & 3 & 2 & 1 & 1 \\
\hline 5 & 4 & 5 & 3 & 3 & 1 & 1 \\
\hline 6 & 5 & 4 & 2 & 3 & 0 & 1 \\
\hline 7 & 5 & 5 & 2 & 3 & 0 & 1 \\
\hline 8 & 5 & 4 & 2 & 3 & 0 & 0 \\
\hline 9 & 5 & 5 & 2 & 3 & 0 & 1 \\
\hline$X \pm s(X)$ & $4,66 \pm 0,17$ & $4,66 \pm 0,18$ & $2,56 \pm 0,18$ & $2,89 \pm 0,11$ & $0,33 \pm 0,17$ & $0,78 \pm 0,15$ \\
\hline CV (\%) & 10,7 & 11,6 & 20,6 & 11,5 & 150,0 & 56,7 \\
\hline IC & 0,38 & 0,41 & 0,41 & 0,26 & 0,39 & 0,34 \\
\hline
\end{tabular}

$\mathrm{X} \pm \mathrm{s}(\mathrm{X})$ : média \pm erro-padrão; CV $(\%)$ : coeficiente de variação; IC: intervalo de confiança $(\mathrm{P}=0,95)$ Nível organizacional: $0-1=$ Distribuição em feixe modelado, núcleo fusiforme; $2-3=$ Distribuição monótona, núcleo rarefeito; $4-5$ = Distribuição sem polaridade, não se modela.

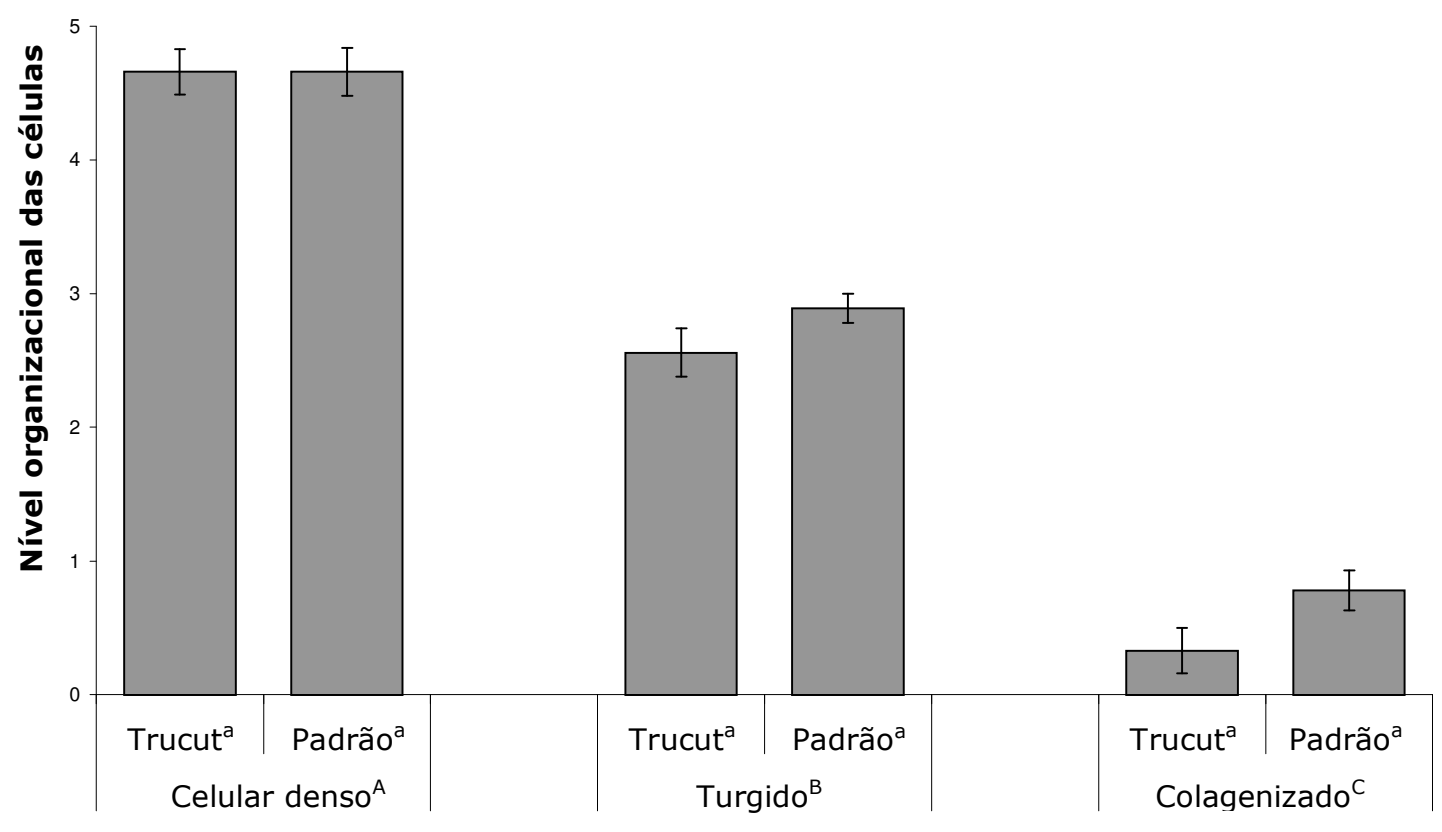

Plano tecidual e método de colheita

Figura 3 - Nível organizacional das células de acordo com o plano tecidual e o método de colheita em amostras de tecido ovariano em éguas. 
ABREU, R.G. et al. Técnica comparativa de biopsia ovariana em éguas. PUBVET, Londrina, V. 5, N. 26, Ed. 173, Art. 1165, 2011.

A Tab.3 e Fig.4 demonstram a terceira avaliação.

Tabela 3 - Cromatismo do núcleo celular de acordo com o plano tecidual e método de colheita de amostras de tecido ovariano de éguas.

\begin{tabular}{ccccccc}
\hline \multirow{2}{*}{ Animal } & \multicolumn{6}{c}{ Cromatismo do núcleo celular(0 - 5) } \\
\cline { 2 - 7 } & \multicolumn{2}{c}{ Celular denso } & \multicolumn{2}{c}{ Turgido } & \multicolumn{2}{c}{ Colagenizado } \\
\cline { 2 - 7 } & Trucut & Padrão & Trucut & Padrão & Trucut & Padrão \\
\hline 1 & 5 & 4 & 3 & 2 & 1 & 0 \\
3 & 5 & 4 & 3 & 3 & 1 & 0 \\
4 & 5 & 5 & 3 & 2 & 1 & 0 \\
5 & 4 & 5 & 3 & 2 & 1 & 0 \\
6 & 5 & 4 & 3 & 3 & 1 & 1 \\
7 & 4 & 5 & 3 & 2 & 1 & 1 \\
8 & 4 & 4 & 3 & 2 & 1 & 1 \\
9 & 4 & 5 & 3 & 2 & 1 & 1 \\
\hline X \pm s(X) & $4,44 \pm 0,18$ & $4,56 \pm 0,18$ & $3,00 \pm 0,00$ & $2,22 \pm 0,15$ & $1,00 \pm 0,00$ & $0,56 \pm 0,24$ \\
CV (\%) & 11,9 & 11,6 & 0 & 19,8 & 0 & 130,8 \\
IC & 0,41 & 0,41 & 0 & 0,34 & 0 & 0,56
\end{tabular}

$\mathrm{X} \pm \mathrm{s}(\mathrm{X})$ : média \pm erro-padrão; $\mathrm{CV}(\%)$ : coeficiente de variação; IC: intervalo de confiança $(\mathrm{P}=0,95)$, Cromatismo nuclear: $0-1=$ Hipocromatismo; $2-3=$ Normocromatismo; $4-5=$ Hipercromatismo.

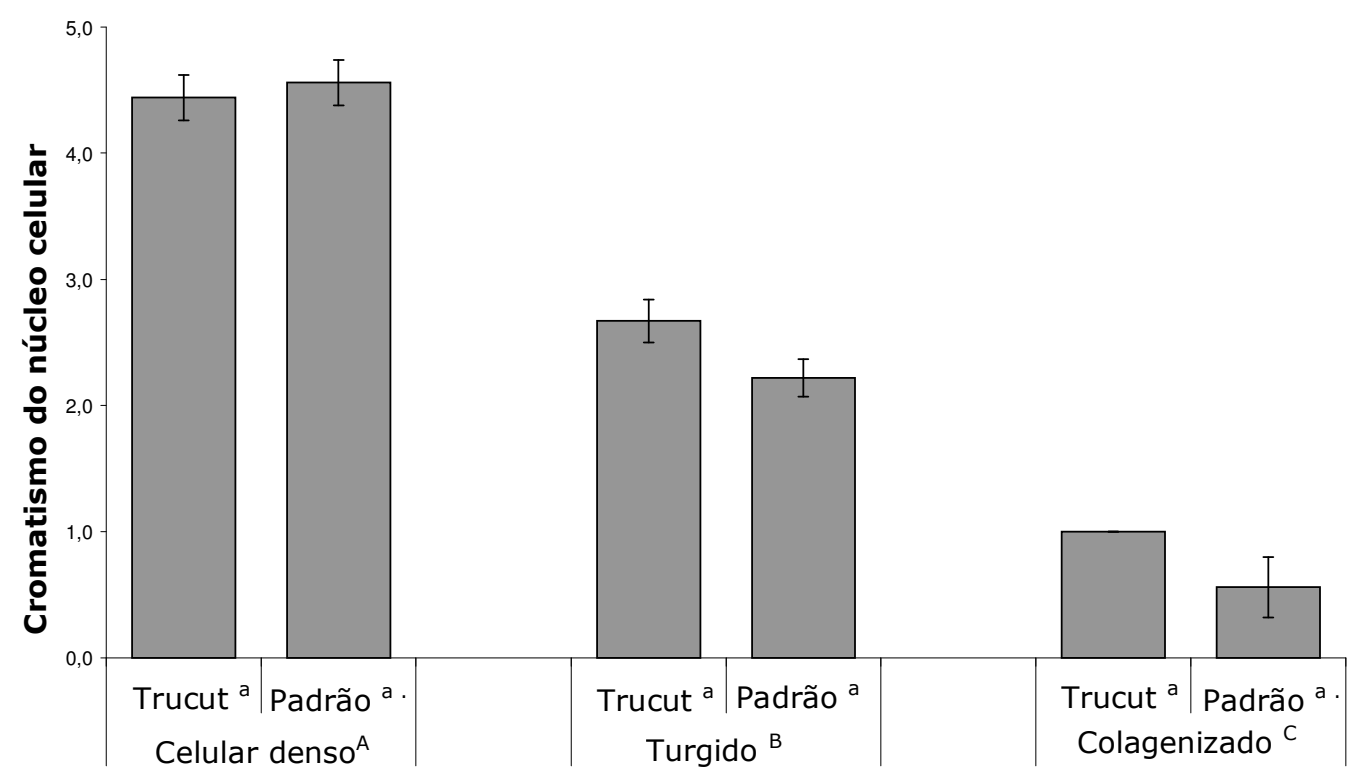

Plano tecidual e método de colheita

Figura 4 - Cromatismo do núcleo celular de acordo com o plano tecidual e método de colheita de amostras de tecido ovariano de éguas. 
ABREU, R.G. et al. Técnica comparativa de biopsia ovariana em éguas. PUBVET, Londrina, V. 5, N. 26, Ed. 173, Art. 1165, 2011.

A característica de cromatismo do núcleo celular não evidenciou diferença significativa na comparação dos métodos de colheita, mostrando a representatividade do método de colheita Trucut em relação ao método padrão (Fig.4). Entre os planos teciduais avaliados, houve diferença significativa, uma vez que o cromatismo do núcleo celular assume padrão diferente para cada composição tecidual.

\section{Discussão}

O procedimento padrão de colheita de material para biopsia é uma técnica realizada com bisturi convencional, extensamente aceita e que mostra poucas limitações na obtenção de amostras da área prescrita (BARBOSA et al. 2005), com dimensões próximas de $15,0 \times 5,0 \times 5,0$ mm, e alteração mínima na qualidade das lâminas histológicas. Em equinos, no caso dos ovários de éguas, o procedimento só ocorre após exérese do órgão. Não há na literatura correspondente, evidências de publicação sobre a colheita de material para biopsia dos ovários em éguas.

A utilização da agulha Trucut no comparativo com o procedimento padrão de colheita, se deu pela obtenção de uma amostra tecidual por secção de um hemicilindro de lesão, permitindo a avaliação histológica através desta técnica (IRION et al. 2006).

Também é importante ressaltar o que Parker et al. (1989) dispos em seus estudos, que um fator muito importante na biopsia por agulha cortante vem a ser o tamanho da lesão, sendo que as de tamanho muito pequeno, ou seja, menores que o diâmetro ou do comprimento mínimo da secção cortante da agulha não são passíveis de serem realizadas biopsias por tal método.

Os planos teciduais (celular denso, turgido e colagenizado), tiveram inspiração no que Dellmann \& Brown (1982) demonstraram. Uma variação morfológica da disposição celular no ovário equino, observada nas várias disposições celulares, de acordo com os estádios em que os folículos se encontram. Isto enfatiza a dificuldade clínica de avaliação sem que se tenha 
ABREU, R.G. et al. Técnica comparativa de biopsia ovariana em éguas. PUBVET, Londrina, V. 5, N. 26, Ed. 173, Art. 1165, 2011.

ferramentas de acesso, para auxílio-diagnóstico, além das já conhecidas (palpação, ultrassonografia e dosagem hormonal).

As comparações sequentes que diferenciaram os planos teciduais (\% de área ocupada por células, nível organizacional das células e cromatismo do núcleo celular), formaram parâmetros representativos entre as técnicas de colheita utilizadas. No caso do cromatismo do núcleo celular, este parâmetro é verificado em fases distintas do ciclo estral (proestro, estro e início da regressão), pela diferenciação de algumas células da teca interna, que assumem um padrão de cromatina mais claro e nucléolos mais evidentes, abundantes nos folículos maduros (DELLMANN \& BROWN, 1982).

Quando a técnica de colheita de material para biopsia dos ovários equinos se faz necessária, um estudo particular é exigido, pois não emergem da literatura disponível, artigos semelhantes ao proposto neste estudo. Técnicas de biopsia em outros órgãos ou de outras espécies, também demonstraram a mesma dificuldade, como as técnicas de biopsia hepática guiadas por ultra-sonografia ou assistidas por laparoscopia foram pouco exploradas na espécie ovina, apesar da reconhecida precisão e segurança relacionadas com o seu uso. De qualquer forma, ainda que tenham sido obtidos resultados positivos com o uso de algumas técnicas e instrumentos diversos, não existem artigos disponíveis que comparem, de forma ampla, os efeitos das técnicas sobre os animais experimentais, nem que confrontem a representatividade e a qualidade das amostras obtidas através das diferentes técnicas (NÉSPOLI et al. 2010).

Também deve-se avaliar, o que mais cortes histológicos seriados, em profundidades diferentes, significariam nos resultados já que, no preparo das lâminas, podem acontecer tecnopatias, artefatos relativos ao procedimento de montagem ou reativos às técnicas de coloração utilizadas.

Vale lembrar que, a parceria com o laboratório de histopatologia é fundamental para a conclusão desta técnica, visto que a variação de planos teciduais nos ovários das éguas, não obedece uma distribuição regular, dependendo do momento fisiológico das estruturas envolvidas na localização 
ABREU, R.G. et al. Técnica comparativa de biopsia ovariana em éguas. PUBVET, Londrina, V. 5, N. 26, Ed. 173, Art. 1165, 2011.

do fragmento colhido pela agulha de biopsia Trucut, valorizando ainda mais a precisão do histotécnico na confecção das lâminas.

A técnica de colheita de amostra ovariana com agulha Trucut, em éguas, pode ser utilizada no futuro, associada à NOTES (cirurgia endoscópica transluminal por orifícios naturais), aprimorando as cirurgias minimamente invasivas, com melhores resultados pós-operatórios (cicatrização, aspecto estético e alta precoce), pelo acesso à cavidade abdominal através de orifícios naturais (boca, uretra, vagina e ânus). Os primeiros relatos experimentais pela NOTES, em animais, foram publicados por Kalloo et al. (2004).

\section{Conclusão}

A técnica de colheita de amostra de ovários de éguas, para biopsia, por agulha cortante, tipo Trucut, mostrou-se eficaz na representatividade em comparação com a técnica de biopsia padrão.

\section{Referências bibliográficas}

BARBOSA, R.P.S.; PAIVA, M.D.E.B.; RODRIGUES, T.L.C.; RODRIGUES, F.G. Valorizando a Biopsia na clínica odontológica, Arquivos em odontologia, Belo Horizonte, v. 41, n. 4, p. 273368, 2005.

BUNCH, S.E.; POLAK, D.M.; HORNBUCKLE, W.E. A modified laparoscopic approach for liver biopsy in dogs, Journal American Veterinary Medical Association, v. 187, c. 10, p. 1032-1035, 1985.

DELLMANN \& BROWN. Histologia Veterinária. Guanabara Koogan, p. 255-266, 1982.

GRUNERT, E.; GREGORY, R.M. Diagnóstico e terapêutica da infertilidade na vaca, Porto Alegre, Sulina, 174p, 1984.

HUMASON, G.L. Animal tissue techniques. 3a ed., San Francisco: WH Freemank, 641p., 1972.

IRION, K.L.; IRION, L.D.; HOCHHEGGER, B. Core Biópsia, Tru-Cut biópsia, punção lancetante ou biópsia por punção com agulha fragmentante tecidual (punção fragmentante - PFrag) ?, Radiologia Brasileira, São Paulo, v. 39, n. 4, 2006.

KALLOO, A.N.; SINGH, V.K.; JAGANNATH, S.B. Flexible transgastric peritoneoscopy: a novel approach to diagnostic and therapeutic interventions in the peritoneal cavity. Gastrointest Endosc, v. 60, p. 114-117, 2004. 
MARTINS, C.F.; VASQUES, L.; NEIS, F.; TARDIN, M.; VISIOLY, V.; FERNANDES, C.E. Biopsia endometrial em vacas bos indicus em regime extensivo de criação com problemas de fertilidade, Ensaios e Ciência. v. 6, n. 2, p. 13-33, 2002.

MICHAEL EDWARDS, F.R.C.S. TruCut needle Biopsy, Woodlands Hospital, Pantogen $®$ Customizable Script, p. 5, 2003.

NÉSPOLI, P.B.; GHELLER, V.A.; PEIXOTO, P.V.; FRANÇA, T.N.; CARVALHO, A.U.; GODOY DE ARAÚJO, D.K.; MALM, C. Avaliação de técnicas de biópsia hepática em ovinos, Departamento de Clínica Médica Veterinária, UFMT, Cuiabá, Pesquisa Veterinária Brasileira v.30, n. 1, p. 2936,2010

PARKER, S.H.; HOPPER, K.D.; YAKES, W.F.; GIBSON, M.D.; OWNBEY, J.L.; CARTER, T.E. Image-directed percutaneous biopsies with a biopsy gun; Radiology, Easten, v. 171, c. 3, p. 663-669, 1989.

PIMENTEL, C.A. Infertilidade em bovinos. In: Correa, F.R.; Schild, A.L.; Mendez, M.C. Doenças de ruminantes e eqüinos, Universidade Federal de Pelotas, v. 11, p. 559-589, 1998.

PIMENTEL GOMES, F. Curso de Estatística Experimental, $3^{a}$ Ed. Piracicaba, Escola Superior de Agricultura "Luiz de Queiroz", USP, 404 p., 1966.

RICKETTS, S.W. Uterine structural normality and abnormalities. IN: Ricketts, S.W. Equine stud medicine course. British Equine Veterinary Association: Newmarket, 10a ed., p.70-77, 2005.

VAN CAMP, S.D. Ancillary tests for assessment of the reproductive systen. The Veterinary Clínics of North American. Food Animal Practice, [SI], v. 8, n. 2, p. 347-360, 1992. 